\title{
The Isoform-Specific Region of the Na,K-ATPase Catalytic Subunit: Role in Enzyme Kinetics and Regulation by Protein Kinase $\mathrm{C}^{\dagger}$
}

\author{
Marie-Josée Duran,* Sandrine V. Pierre, ${ }^{\S}$ Deborah L. Carr, and Thomas A. Pressley \\ Department of Physiology, Texas Tech University Health Sciences Center, 4th Street, Lubbock, Texas 79430
}

Received May 14, 2004; Revised Manuscript Received September 21, 2004

\begin{abstract}
Comparisons of the primary structures of the Na,K-ATPase $\alpha$-isoforms reveal the existence of regions of structural divergence, suggesting that they are involved in unique functions. One of these regions is the isoform-specific region (ISR), located near the ATP binding site in the major cytoplasmic loop. To evaluate its importance, we constructed mutants of the rodent wild-type $\alpha 1$ and $\alpha 3$ isoforms in which the ISR was replaced with irrelevant sequences, i.e., the analogous region from the rat gastric $\mathrm{H}, \mathrm{K}-\mathrm{ATPase}$ catalytic subunit or a region from the human c-myc oncogene. Opossum kidney (OK) cells were transfected with wild-type rat $\alpha 1, \alpha 3$, or their corresponding chimeras and selected in ouabain. Introduction of either mutant produced ouabain-resistant colonies, consistent with functional expression of the chimeric protein and indicating that the ISR is not essential for overall $\mathrm{Na}, \mathrm{K}-\mathrm{ATPase}$ function. The introduced chimeras were then characterized enzymatically by measuring the relative rate of $\mathrm{K}^{+}$and $\mathrm{Li}^{+}$ deocclusions. Results showed that exchanges of both $\alpha 1$ and $\alpha 3$ ISRs significantly modified the sensitivity for the enzyme to either $\mathrm{K}^{+}$or $\mathrm{Li}^{+}$. Subsequent treatment of the cells with phorbol esters revealed an altered $\mathrm{Na}, \mathrm{K}$-ATPase transport in response to protein kinase $\mathrm{C}$ activation for the $\alpha 1$ chimeras. No changes were observed for the $\alpha 3$ isoform, suggesting that it is not sensitive to PKC regulation. These results demonstrated that the ISR plays an important role in ion deocclusion and in the response to PKC (only for the $\alpha 1$ isoform).
\end{abstract}

The Na,K-ATPase, which catalyzes the extrusion of $\mathrm{Na}^{+}$ and the absorption of $\mathrm{K}^{+}$at the expense of metabolic energy derived from ATP, consists of at least two subunits, $\alpha(110$ $\mathrm{kDa})$ and $\beta(55 \mathrm{kDa})$, existing as several isoforms. The $\alpha$ subunit, representing the catalytic component of the enzyme, is a membrane-spanning protein expressed as four isoforms $(\alpha 1, \alpha 2, \alpha 3$, and $\alpha 4)$ with differences in enzyme kinetics and response to second messengers (1). Comparisons of the primary structures of the rat isoforms have revealed regions of structural divergence that could be involved in isoformspecific functions. A major site of sequence divergence among the $\alpha$ isoforms is the isoform-specific region (ISR ${ }^{1}$; Figure 1) (2). This 11-amino acid sequence is located in the major cytoplasmic loop between TM4 and TM5 near the ATP binding site (2). Alignment and homology comparison of the rat $\alpha$ ISR amino acid sequences (Figure 1) reveal significant diversity among the isoforms. Indeed, while the rat $\alpha 1$ ISR shares $27 \%$ of homology with the $\alpha 4$ ISR, the $\alpha 1$ and $\alpha 2$ ISRs, as well as the $\alpha 1$ and $\alpha 3$ ISRs, share only $9 \%$ of their residues.

Because of its proximity to the ATP binding site, we speculated that the replacement of the ISR by unrelated sequences would alter the enzymatic properties of the

\footnotetext{
$\dagger$ This project was supported in part by a grant from the National Center for Research Resources, RR-19799.

* To whom correspondence should be addressed: Department of Physiology, Texas Tech University Health Sciences Center, 3601, 4th street, Lubbock TX 79430, USA. Phone: (806) 743-4056. Fax: (806) 743-1512. E-mail: mariejosee.duran@ttuhsc.edu.

$\S$ Current address: Department of Pharmacology and Therapeutics, Medical College of Ohio, Arlington Ave., Toledo, OH 43614, USA.

${ }^{1}$ Abbreviations: ISR, isoform-specific region; OK, opossum kidney; PKC, protein kinase C; PMA, phorbol myristate acetate.
}

molecule. In a previous study, we have shown that the $\alpha 1$ ISR is essential in protein kinase $\mathrm{C}$ (PKC) regulation (2). The present study aims to investigate further the importance of the Na,K-ATPase $\alpha 1$ ISR and to describe the potential role of the $\alpha 3$ ISR to the kinetics and regulation of the enzyme, using a mutagenesis/heterologous expression strategy. Results show that transfections of each chimera produced viable colonies, suggesting that swapping of the ISR did not compromise the expression of the protein and the overall Na,K-ATPase enzymatic function. While substitutions of the $\alpha 1$ and $\alpha 3$ ISRs with unrelated sequences induced changes in both $\mathrm{K}^{+}$and $\mathrm{Li}^{+}$sensitivities of the enzyme, regulation of the pump-mediated transport by $\mathrm{PKC}$ was only impaired in mutants for the $\alpha 1$ ISR.

\section{EXPERIMENTAL PROCEDURES}

Preparation of Rat $\alpha 1$ and $\alpha 3^{*}$ Isoforms. Rat wild-type $\alpha 1$ and $\alpha 3$ cDNAs, a gift from Dr. J. B. Lingrel and colleagues (3), were subcloned by our laboratory into pGEM3Z (Promega, Madison, WI) as described (4). A variant of the rat wild-type $\alpha 3$ isoform, designated $\alpha 3^{*}$, was constructed by site-directed mutagenesis (Q108R and N119D) to obtain an isoform resistant to micromolar concentrations of ouabain (5). The use of an ouabain-resistant $\alpha 3$ isoform allowed us to employ the ouabain-selection strategy described below. The structure of the $\alpha 3^{*}$ mutant cDNA was confirmed by direct sequencing.

Construction of the Chimeras. The rat $\alpha 1$ and $\alpha 3 *$ cDNAs were used to prepare chimeric molecules in which the ISR of $\alpha 1$ and $\alpha 3 *$ was substituted with two unrelated sequences, the analogous region from the rat gastric H,K-ATPase 


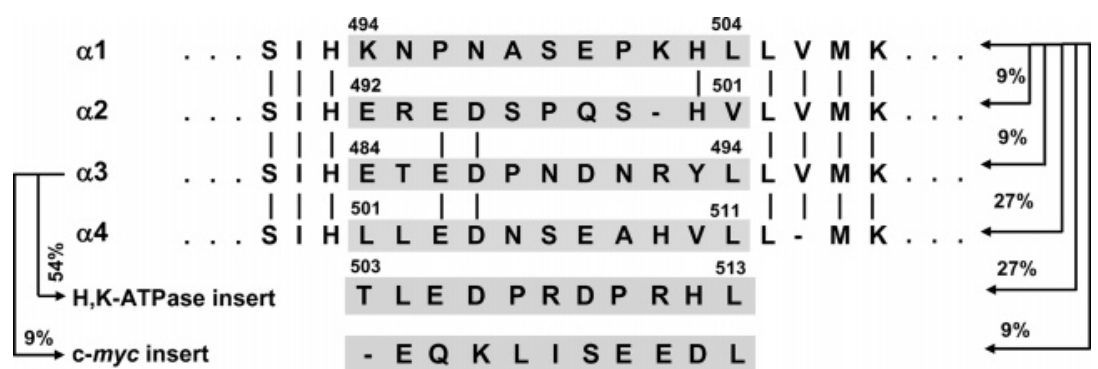

FIGURE 1: Alignment of the rat $\alpha 1, \alpha 2, \alpha 3$, and $\alpha 4$ isoform-specific region (ISR, shaded) amino acid sequences with the rat H,K-ATPase and human c-myc sequences used in this study. The percent homology between the $\alpha 1$ ISR and the other sequences (other $\alpha$ isoform ISRs, $\mathrm{H}, \mathrm{K}-\mathrm{ATPase}$, and c-myc inserts) is shown.

\begin{tabular}{|c|c|c|c|c|}
\hline target genes & sequences $\left(5^{\prime}\right.$ to $\left.3^{\prime}\right)$ & $\begin{array}{l}\text { position in } \\
\text { the plasmid }\end{array}$ & product size & $\begin{array}{c}\text { annealing } \\
\text { temperature }\end{array}$ \\
\hline Na,K-ATPase $\alpha 1, \alpha 1 \mathrm{HK} \alpha 1, \alpha 1 m y c \alpha 1$ & $\begin{array}{l}\text { CAC TGC TTA ACT GGC TT (S) } \\
\text { CCT CGG CTC AAA TCT GT (AS) }\end{array}$ & $\begin{array}{l}8595-8611 \\
200-216\end{array}$ & $268 \mathrm{bp}$ & $40^{\circ} \mathrm{C}$ \\
\hline $\mathrm{Na}, \mathrm{K}-\mathrm{ATPase} \alpha 3^{*}, \alpha 3^{*} \mathrm{HK} \alpha 3^{*}, \alpha 3^{*} m y c \alpha 3^{*}$ & $\begin{array}{l}\text { CAC TGC TTA ACT GGC TT (S) } \\
\text { CAC CTC CTC CGC ATT C (AS) }\end{array}$ & $\begin{array}{l}8595-8611 \\
581-596\end{array}$ & $648 \mathrm{bp}$ & $40^{\circ} \mathrm{C}$ \\
\hline
\end{tabular}

${ }^{a}$ To amplify the chimeras, we used sense primers directed against the pRC/CMV promoter region of the recombinant plasmid used for transfection and antisense primers directed against the $\alpha 1$ or $\alpha 3 *$ isoform sequences. $(\mathrm{S})=$ sense, $(\mathrm{AS})=$ antisense.

catalytic subunit and a region from the human c-myc oncogene. To achieve these substitutions, two silent mutations were introduced in rat $\alpha 1$ and $\alpha 3^{*}$ cDNAs by conventional site-directed mutagenesis as described earlier by Pierre et al. (2), creating unique sites for digestion by the restriction enzymes ClaI and AgeI without altering the encoded amino acids. To perform the exchange of the ISRs with the unrelated sequences, the rat $\alpha 1$ and $\alpha 3 *$ cDNAs were digested by $C l a \mathrm{I}$ and $A g e \mathrm{I}$ endonucleases and nucleotide sequence encoding a region from the rat gastric $\mathrm{H}, \mathrm{K}-\mathrm{ATPase}$ catalytic subunit, TLEDPRDPRHL, or from the human c-myc oncogene, EQKLISEEDL, was inserted instead of the ISR into the cloned $\alpha 1$ isoform or the $\alpha 3^{*}$ mutant. The oligonucleotides used to construct these mutants were ATCGATTCACACTCTGGAGGATCCGCGCGACCCCCGGCACTTGCTAGTGATGAAGGGGGCCCCAGAAAGGATACTGGACCGGT and its complement for the rat gastric H,K-ATPase insert, and ATCGATTCACAAGGAGCAAAAGCTCATTTCTGAAGAGGACTTGCTAGTGATGAAGGGGGCCCCAGAAAGGATACTGGACCGGT and its complement for the human c-myc insert, where underlined and double-underlined bases represent, respectively, the ClaI and the AgeI restriction sites. The structures of the constructed chimeras, designated $\alpha 1 \mathrm{HK} \alpha 1, \alpha 1 m y c \alpha 1$, $\alpha 3 * \mathrm{HK} \alpha 3^{*}$, and $\alpha 3 * m y c \alpha 3 *$, were confirmed by restriction analysis and direct sequencing of the altered region. The rat gastric H,K-ATPase sequence was chosen because of its homology with the Na,K-ATPase ISR (i.e., 27 and 54\% identity with the $\alpha 1$ and $\alpha 3$ ISRs, respectively; Figure 1) and the human c-myc oncogene was selected as a totally unrelated sequence ( $9 \%$ homology with either $\alpha 1$ or $\alpha 3$ ISRs; Figure 1).

Subcloning, Heterologous Expression in Mammalian Cells, and Selection. cDNAs encoding $\alpha 1, \alpha 3^{*}$ and the chimeras were subcloned into the eukaryotic expression vector $\mathrm{pRC} /$ CMV (Invitrogen, San Diego, CA) as previously described (2).

Heterologous expression of the different constructs was achieved by transfection of opossum kidney (OK) cells using a cationic liposome preparation (2). Transfected OK cells expressing the introduced ouabain-resistant $\mathrm{Na}, \mathrm{K}$-ATPase constructs were selected for their ability to grow under 3 $\mu \mathrm{M}$ ouabain, a concentration sufficient to kill untransfected OK cells. The colonies obtained were then expanded in ouabain-containing medium to produce stable cell lines.

Total RNA Extraction and Real-Time PCR. The structure and level of expression of the chimeras in recipient cells was evaluated by examination of the expressed mRNAs. After removal of medium from 60-mm culture dishes, total RNA was isolated and reverse-transcribed and the corresponding cDNAs were amplified by real-time PCR using the LightCycler apparatus (Roche). SYBR Green, which has a high affinity for double-stranded DNA (dsDNA) and exhibits enhancement of fluorescence upon binding to the dsDNA, was chosen as the fluorescent dye. Different sets of specific oligonucleotide primers (Table 1) were designed using Vector NTI 7 (InforMax Inc., Frederick, MD) to confirm the expression of the chimera's mRNAs in OK cells. Sense primers were designed to hybridize the pRC/CMV promoter region of the recombinant plasmid used for transfection, while antisense primers had their target in either the $\alpha 1$ isoform or the $\alpha 3^{*}$ mutant DNA sequences. Using this strategy, only the introduced $\alpha 1, \alpha 3^{*}$ isoforms and their respective chimeras will be amplified. Each reaction contained $2 \mu \mathrm{L}$ of cDNA from the reverse-transcribed RNAs, 3 $\mathrm{mM} \mathrm{MgCl}_{2}, 0.5 \mu \mathrm{M}$ of each primers and, $1 \times$ of FastStart DNA Master SYBR Green I mix (Roche) in a $20 \mu \mathrm{L}$ final volume. Samples were then placed in the LightCycler instrument and underwent the following thermal cycling profile: cDNA was denaturated by a preincubation of $30 \mathrm{~s}$ at $95^{\circ} \mathrm{C}$ and the template was amplified for 35 cycles of (1) denaturation for $1 \mathrm{~s}$ at $95^{\circ} \mathrm{C}$; (2) annealing at $40{ }^{\circ} \mathrm{C}$ for 10 $\mathrm{s}$; (3) extension at $72{ }^{\circ} \mathrm{C}$ for $25 \mathrm{~s}$. The increase in fluorescence, dependent on the initial template concentration, was acquired after each extension phase at 86 and $88^{\circ} \mathrm{C}$ for $\alpha 1$ and $\alpha 3^{*}$ constructs, respectively, a temperature above the $T_{\mathrm{m}}$ of the primer dimers and below the $T_{\mathrm{m}}$ of the specific PCR product (Figures 2D and 3D), thus minimizing the 


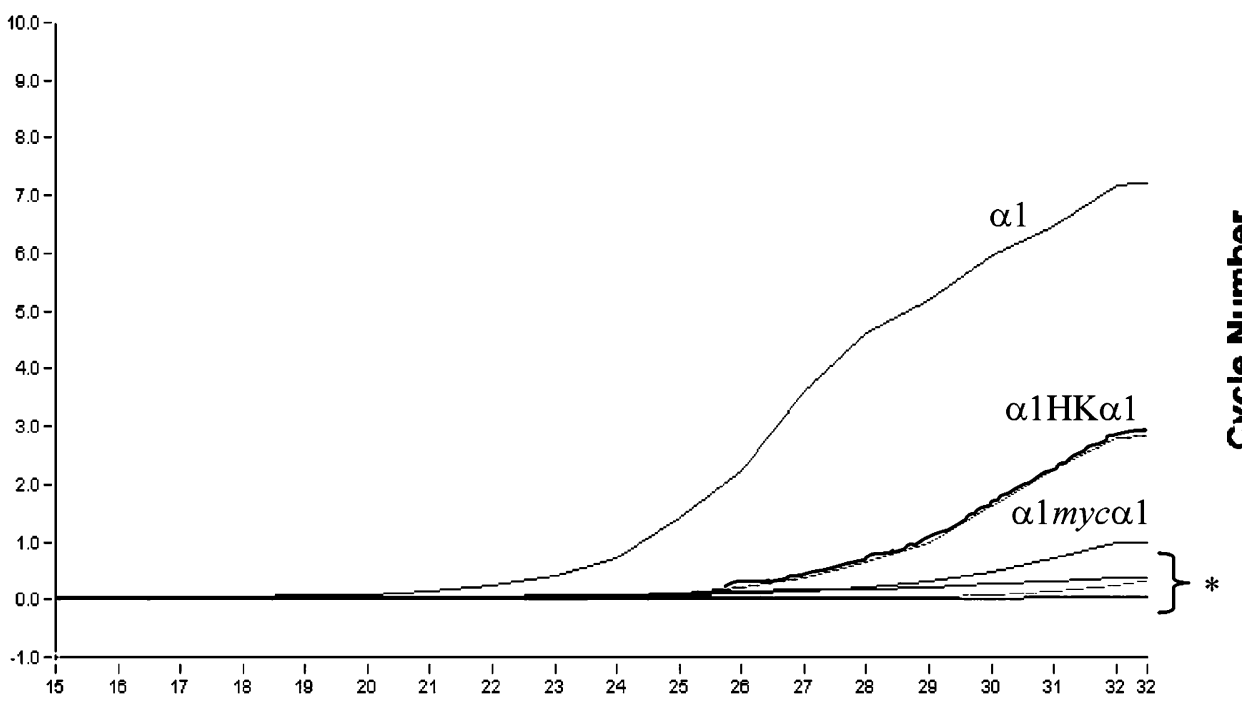

Cycle Number

C

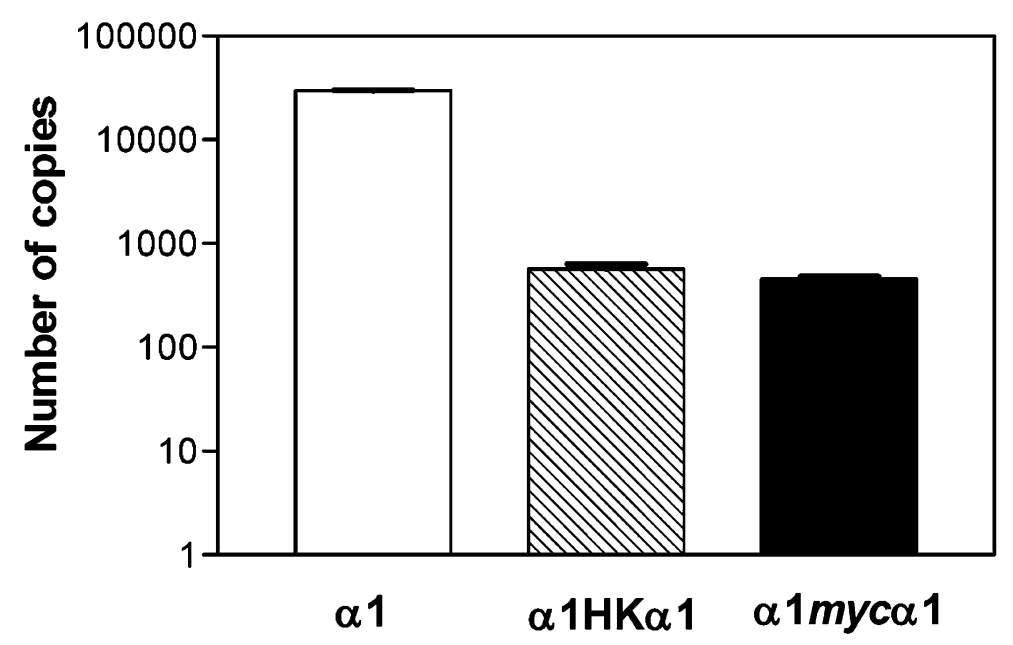

B

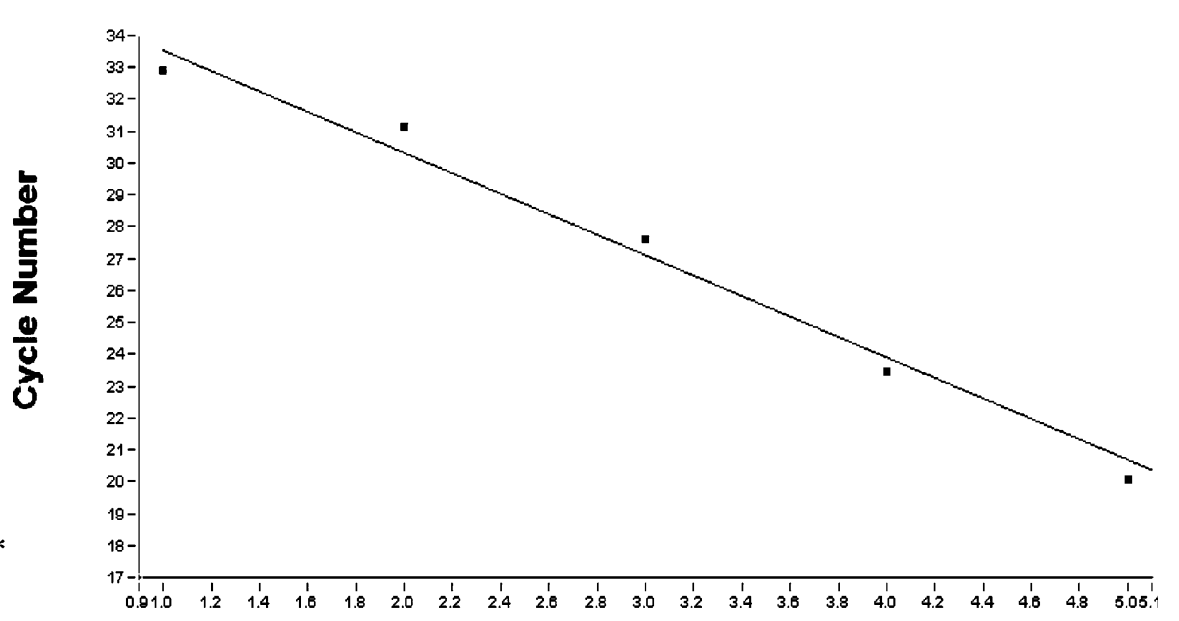

Log Concentration

D

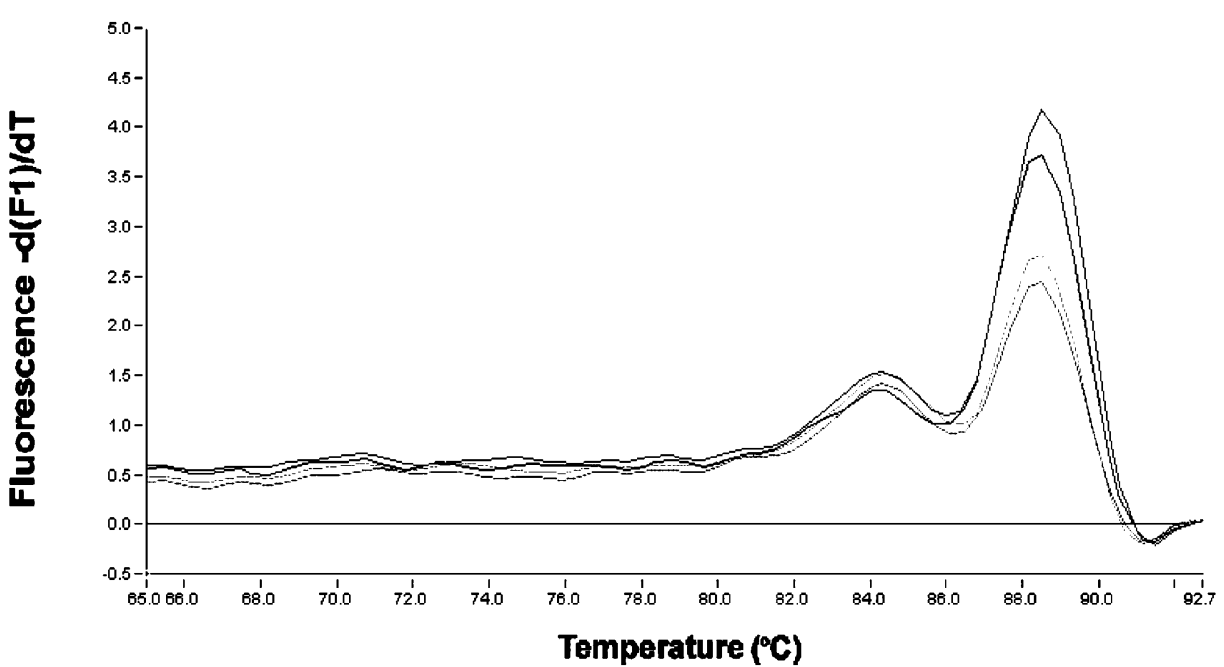

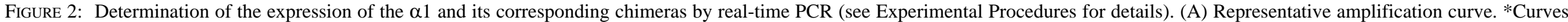

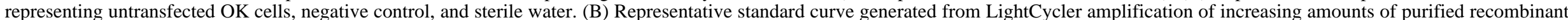

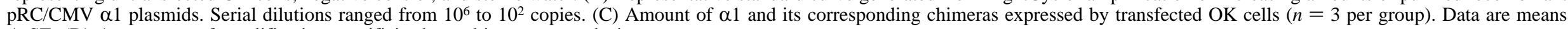
\pm SE. (D) Assessment of amplification specificity by melting curve analysis. 
acquisition of nonspecific fluorescence intensities. After amplification, a melting curve was generated by cooling the samples to $55^{\circ} \mathrm{C}$ for $30 \mathrm{~s}$ and slowly heating the samples at $0.1{ }^{\circ} \mathrm{C} / \mathrm{s}$ to $95{ }^{\circ} \mathrm{C}$ while the fluorescence was measured continuously. The LightCycler run was concluded with a 35 ${ }^{\circ} \mathrm{C}$ incubation for $30 \mathrm{~s}$. Product identity was confirmed by electrophoresis on a $1 \%$ agarose gel stained with ethidium bromide.

To quantify the number of expressed chimeras in transfected OK cells, dilution series of either the recombinant $\alpha 1$ or $\alpha 3^{*}$ plasmids were used as PCR templates in each real-time PCR run to generate a standard curve.

Membrane Purification. Crude plasma membranes were isolated from confluent monolayers of untransfected and ouabain-resistant transfected OK cells by differential centrifugation of lysates, followed by extraction in sodium iodide, as described $(5,6)$. Protein concentrations were determined by the method of Lowry et al. (7).

Relative Rates of $\mathrm{K}^{+} / \mathrm{Li}^{+}$Deocclusions. The ouabainsensitive $\mathrm{Na}^{+}$-ATPase activity was determined from the hydrolysis of radiolabeled ATP in isolated membranes from transfected cells as described by Petrosian et al. (8). To assess the relative rate of deocclusion, various concentrations of either $\mathrm{KCl}$ or $\mathrm{LiCl}$, ranging from 0 to $5 \mathrm{mM}$, were tested. Results were standardized to the ouabain-sensitive $\mathrm{Na}^{+}$ATPase estimate measured in the absence of either $\mathrm{K}^{+}$or $\mathrm{Li}^{+}$.

Active Transport. Pump-mediated transport was assessed in transfected cells grown in 60-mm culture dishes by measuring the ouabain-sensitive uptake of the $\mathrm{K}^{+}$congener ${ }^{86} \mathrm{Rb}^{+}$as described (8). The effect of PKC activation on active transport was determined by treating confluent monolayers for $5 \mathrm{~min}$ with the DMSO vehicle (dimethyl sulfoxide, Sigma, St. Louis, MO), designated as the untreated group, or with $10 \mu \mathrm{M}$ phorbol ester agonist PMA (phorbol myristate acetate, Sigma), diluted in DMSO, before the addition of radiolabeled $\mathrm{Rb}^{+}$.

Structure Modeling. The availability of the crystal structure coordinates of the sarcoplasmic reticulum $\mathrm{Ca}^{2+}$-ATPase isoform $1(9,10)$ allowed us to perform structure comparison and homology modeling. We first performed an initial sequence alignment of the $\mathrm{Ca}^{2+}$-ATPase and the rat $\mathrm{Na}, \mathrm{K}$ ATPase $\alpha 1$ isoform using the Align X application of Vector NTI 7 (Informax Inc.), based on the Clustal W algorithm. Then, using the ProModII software run on the SWISSMODEL server $(11,12)$, we were able to generate a structural model of the rat Na,K-ATPase $\alpha 1$ isoform and its corresponding chimeras based on the known sarcoplasmic reticulum $\mathrm{Ca}^{2+}$-ATPase structure (PDB ID code: 1EUL). In brief, after superimposing the sequence of interest to the known sequence, the PromodII software generates a framework, builds the nonconserved loops, and then refines the model by energy minimization and molecular dynamics. The structural model was visualized and manipulated using Deep View Swiss-Pdb Viewer software (http://www.expasy.org/ spdbv/).

Statistical Analyses. Results are expressed as means \pm SE. Statistical analysis was performed using nonparametric and parametric tests as needed using the GraphPad Prism 2.0 software (GraphPad Software Inc., San Diego, CA). Values of $p<0.05$ were considered statistically significant.

\section{RESULTS}

The ISR Is Not Critical for Overall Enzymatic Function. To determine directly whether the ISR of $\alpha 1$ was critical for enzymatic function, we generated protein chimeras in which the ISR was replaced with unrelated sequences. The more conservative substitution was the analogous sequence from the rat gastric $\mathrm{H}, \mathrm{K}$-ATPase catalytic subunit, a member of the P-type class 2 superfamily of transport ATPases such as the Na,K-ATPase. Homology comparisons of the rat gastric $\mathrm{H}, \mathrm{K}$-ATPase amino acid sequence with the $\alpha 1$ or $\alpha 3$ ISRs revealed 27 and 54\% of similarity, respectively (Figure 1). The more risky substitution was performed using a region from the human c-myc oncogene, a completely unrelated sequence showing little homology (9\%) with the $\alpha 1$ and $\alpha 3$ ISRs. The resulting chimeric molecules, $\alpha 1 \mathrm{HK} \alpha 1$ and $\alpha 1$ myc $\alpha 1$, as well as the wild-type rat $\alpha 1$ were introduced into OK cells in culture by DNA-mediated gene transfer. To select for recipient cells, we took advantage of the ability of the rat $\alpha 1$ to confer ouabain resistance when expressed in sensitive cells, a strategy exploited by many laboratories $(5,13)$. As expected, the wild-type isoform produced viable colonies after selection in concentrations of ouabain sufficient to kill nontransfected OK cells, consistent with its relatively low affinity for the glycoside. More to the point of this project, both $\alpha 1 \mathrm{HK} \alpha 1$ and $\alpha 1$ myc $\alpha 1$ also conferred ouabain resistance, suggesting that replacement of the $\alpha 1$ ISR does not compromise overall $\mathrm{Na}, \mathrm{K}$-ATPase function.

The same mutagenesis strategy was adopted to produce $\alpha 3^{*} \mathrm{HK} \alpha 3^{*}$ and $\alpha 3^{*} m y c \alpha 3^{*}$ chimeras in which the $\alpha 3$ ISR was replaced with the H,K-ATPase and myc sequences, respectively. As expected, the control $\alpha 3^{*}$ was fully capable of conferring ouabain resistance. Both constructed $\alpha 3^{*}$ chimeras also conferred the resistant phenotype, showing that, similarly to $\alpha 1$, the $\alpha 3$ ISR is not critical for overall enzymatic function.

The H,K-ATPase- and myc-Substituted Chimeras Are Efficiently Expressed by OK Cells. Confirmation of the introduced chimeras' structures was achieved by real-time PCR after extraction of total RNA from the transfected or untransfected OK cells. For this purpose, different specific oligonucleotide primers were designed (for details, see Table 1) to amplify only sequences from the introduced $\alpha 1, \alpha 3^{*}$ isoforms and their respective chimeras. To amplify cDNA from the introduced isoforms and chimeras, we used sense primers directed against the $\mathrm{pRC} / \mathrm{CMV}$ promoter region of the recombinant plasmid used for transfection and antisense primers directed against either the $\alpha 1$ or the $\alpha 3^{*}$ sequences. After reverse-transcription of the total RNA isolated from transfected or untransfected OK cells, and realtime PCR with the described primers, the amplification curves showed amplification for $\alpha 1$ and its corresponding chimeras (Figure 2A) as well as for $\alpha 3^{*}$ and its corresponding chimeras (Figure 3A) but, as expected, not for the untransfected OK cells. PCR product identification was performed by melting curve analysis (Figures 2D and 3D) and electrophoresis. Since the melting curve of a product is dependent upon its GC content, length, and sequence composition, specific amplification can be distinguished from nonspecific amplification by examining the melting curve. We also verified the PCR product by confirming the correct size of amplicons after agarose gel electrophoresis (data not 
$\mathbf{A}$

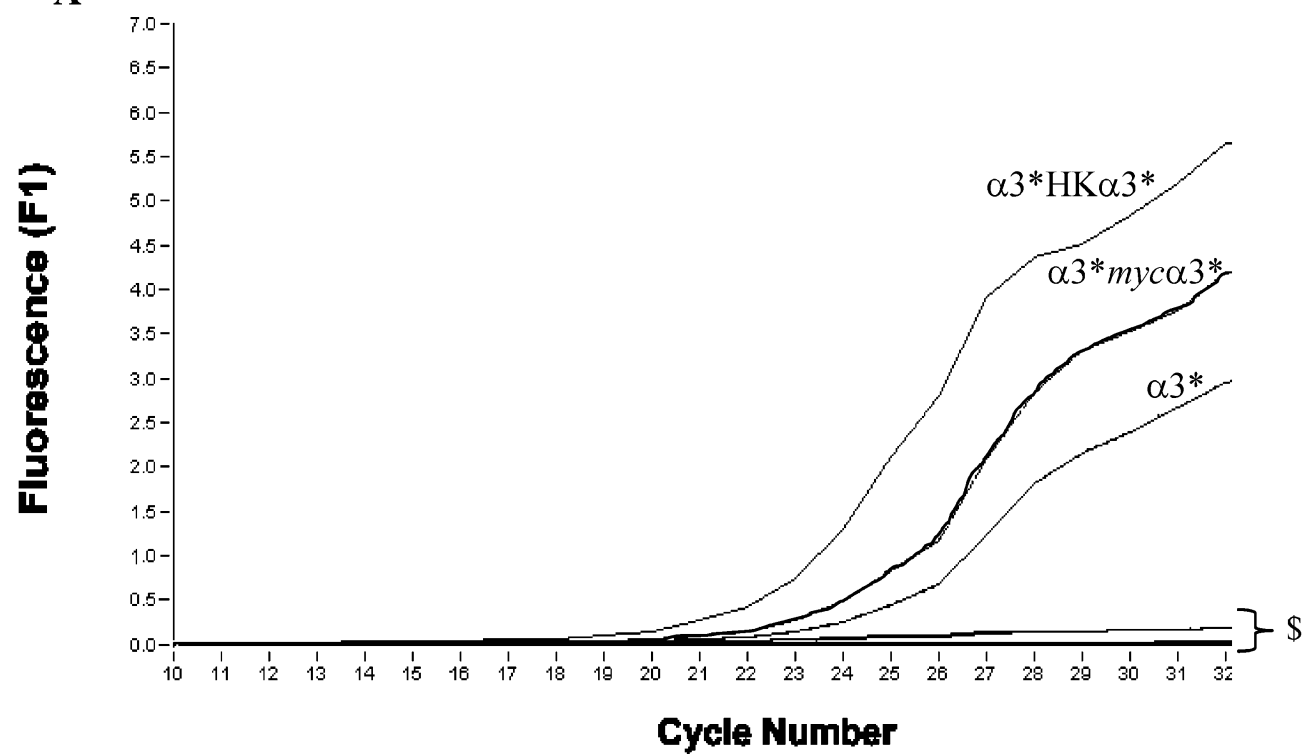

B
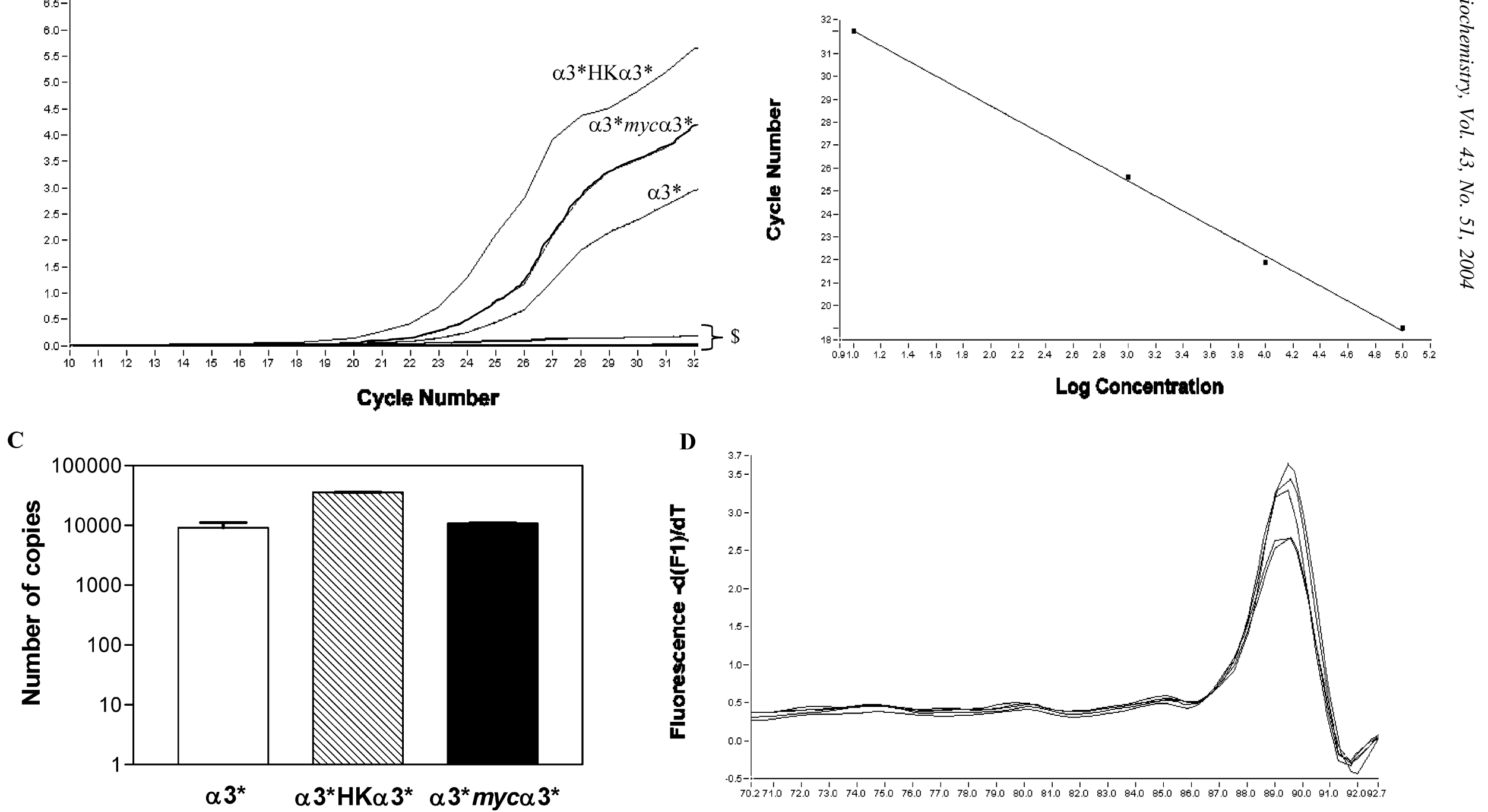

D

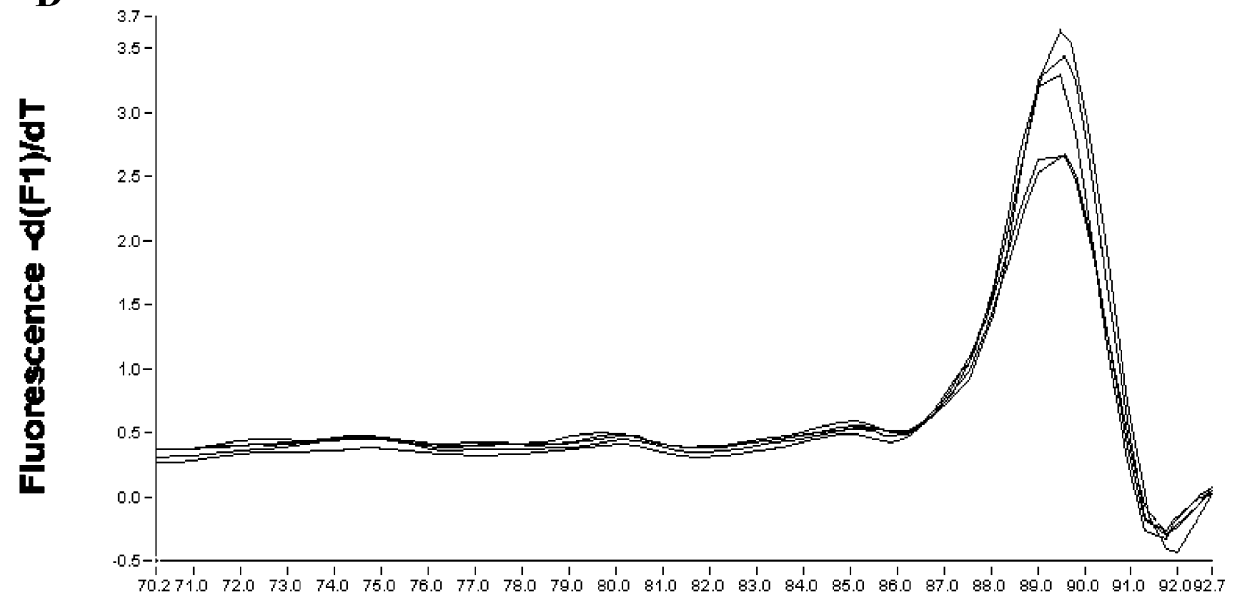

Temperature ( $\left.{ }^{\circ} \mathrm{C}\right)$

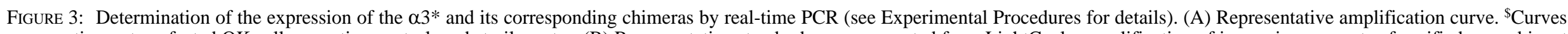

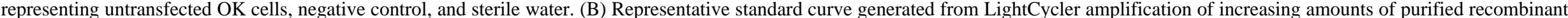

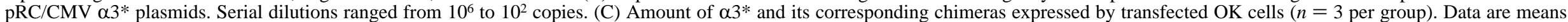
\pm SE. (D) Assessment of amplification specificity by melting curve analysis. 
shown). Both approaches showed the correct size and melting pattern, e.g., a single peak at 88 and $89{ }^{\circ} \mathrm{C}$ for the $\alpha 1$ and $\alpha 3^{*}$ cDNA amplifications, respectively, for the amplified fragments. Specific controls, which included a negative control with no cDNA in the reaction mixture and sterile water, always yielded the expected results (Figures 2A and $3 \mathrm{~A})$.

Standard curves were generated from cDNAs made from increasing amounts of purified recombinant pRC/CMV $\alpha 1$ or $\alpha 3^{*}$ plasmids. Ten-fold serial dilutions in a range from $10^{6}$ to $10^{2}$ copies were used. The detection limit was 10 copies. Amplification plots of $\alpha 1$ or $\alpha 3 *$ standards were used to plot a linear regression line using the logarithm of template concentration as $X$-axis against the PCR cycle number on the $Y$-axis (Figures $2 \mathrm{~B}$ and $3 \mathrm{~B}$ ). The results show that, while the $\alpha 1$ isoform was highly expressed by transfected OK cells, mRNA expression for $\alpha 1 \mathrm{HK} \alpha 1$ and $\alpha 1$ myc $\alpha 1$ was similar but weak (Figure 2A). Similar amounts of mRNAs were also found for the $\alpha 3^{*}$ isoform and $\alpha 3^{*} m y c \alpha 3^{*}$ chimera (Figure $3 \mathrm{C})$. Expression of the $\alpha 3 * \mathrm{HK} \alpha 3 *$ mRNAs was three times higher than $\alpha 3^{*}$ and $\alpha 3^{*} m y c \alpha 3^{*}$. Because the basal $\mathrm{Rb}^{+}$ uptake measured in the untransfected or the transfected OK cells is similar (i.e., $8.6 \pm 0.5 \mathrm{nmol} \mathrm{K}+/ \mathrm{min} / \mathrm{mg}$ proteins), it is reasonable to think that the amount of functional enzyme at the plasma membrane is limitated by the amount of $\beta$ isoforms expressed by the OK cells and not by the level of expression of the introduced $\alpha$ constructs.

Although the chimeric $\alpha$ mRNAs were not expressed equally, results obtained from the real-time PCR analyses strongly suggest that the chimeric molecules were expressed correctly.

The ISR Influences Enzyme Kinetics. Probably the most dramatic difference in kinetics among the isoforms involves the relative rate of $\mathrm{K}^{+}$deocclusion, the $\mathrm{E} 2(\mathrm{~K}) \rightarrow \mathrm{E} 1$ step of the Na,K-ATPase catalytic reaction (14) that becomes rate limiting at low ATP concentrations. To examine any possible effects the replacement of the ISR could have on deocclusion, we measured the $\mathrm{K}^{+}$and $\mathrm{Li}^{+}$sensitivities of $\mathrm{Na}^{+}$-ATPase activity in membranes isolated from OK cells expressing various constructs. In micromolar concentrations of ATP sufficient to saturate the high-affinity phosphorylation site, the response of $\mathrm{Na}^{+}$-dependent ATP hydrolysis to varying concentrations of either $\mathrm{K}^{+}$or $\mathrm{Li}^{+}$is a convenient and sensitive indication of isoform-specific differences. Indeed, Daly et al. (15) have shown that the $\mathrm{Na}^{+}$-ATPase activity of the $\alpha 1$ and $\alpha 3$ isoforms is inhibited by increasing concentrations of $\mathrm{K}^{+}$, but stimulated for the $\alpha 2$ isoform. Relative $\mathrm{K}^{+}$sensitivity of ouabain-sensitive $\mathrm{Na}^{+}$-ATPase activity in membranes from the different transfected OK cells are represented in Figure 4. The $\mathrm{K}^{+}$-induced inhibition pattern observed in this study for the wild-type $\alpha 1$ isoform (Figure 4A) is comparable to the one obtained by Pierre et al. (2). Exchange of the $\alpha 1$ ISR by either the H,K- or mycsequences increased $\mathrm{K}^{+}$inhibition to a notable extent in the initial phase of the curve as well as for the highest $\mathrm{K}^{+}$ concentrations (Figure 4A). While the $\alpha 3^{*}$ and $\alpha 3 * \mathrm{HK} \alpha 3^{*}$ displayed similar kinetic behavior at high $\mathrm{K}^{+}$concentrations, a remarkable difference was observed in the range of $0-0.4$ $\mathrm{mM}$ (Figure 4B). The most striking difference was found for the $\alpha 3 *$ myc $\alpha 3^{*}$ chimera, which, although displaying an inhibition profile similar to $\alpha 3^{*}$, showed a lower degree of inhibition at high $\mathrm{K}^{+}$concentrations. These ISR-induced
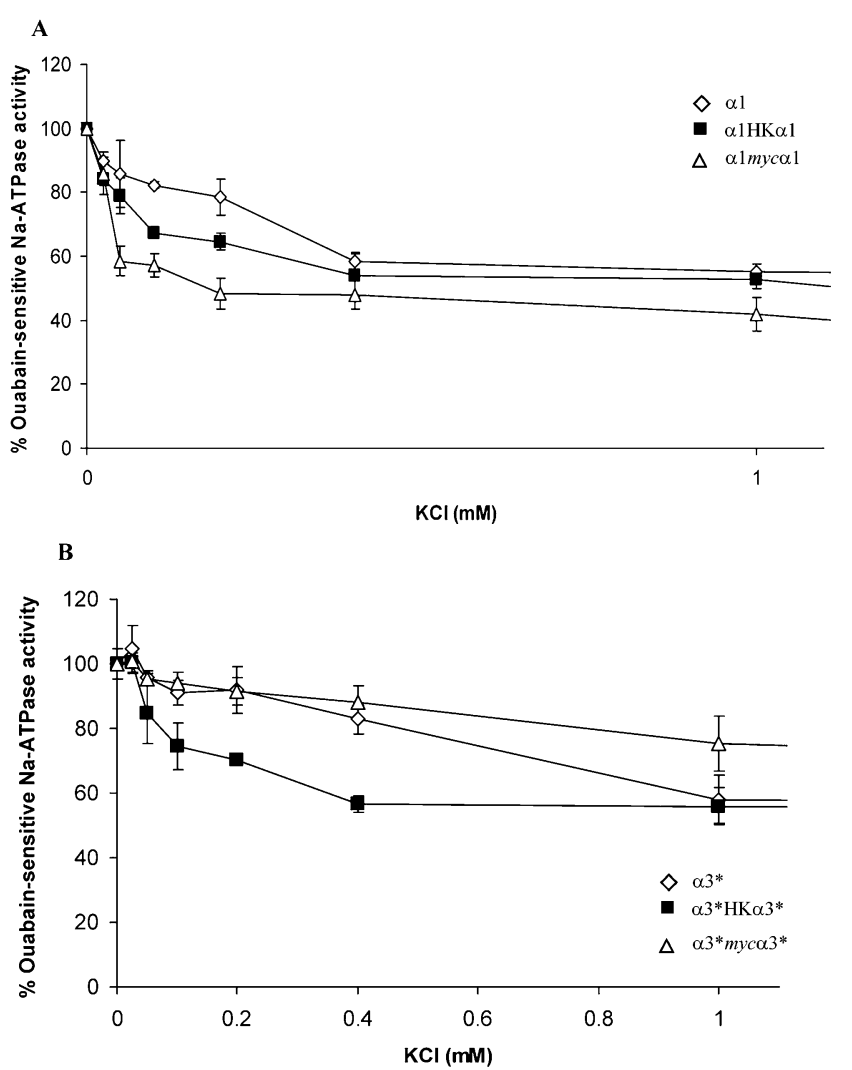

FIGURE 4: Relative $\mathrm{K}^{+}$sensitivity of $\mathrm{Na}^{+}$-ATPase in membranes from transfected cells. Hydrolysis of $\left[\gamma_{-}{ }^{32} \mathrm{P}\right] \mathrm{ATP}$ was measured after $30 \mathrm{~min}$ in the presence of $1 \mu \mathrm{M}$ ATP, $20 \mathrm{mM} \mathrm{NaCl}$, and various concentrations of $\mathrm{KCl}$. Results are presented relative to ouabainsensitive $\mathrm{Na}^{+}$-ATPase activity. To inhibit endogenous $\mathrm{Na}, \mathrm{K}$ ATPase, $3 \mu \mathrm{M}$ ouabain was present in all reactions. (A) Ouabainsensitive $\mathrm{Na}^{+}$-ATPase activity of $\alpha 1$ chimeras. (B) Ouabainsensitive $\mathrm{Na}^{+}$-ATPase activity of $\alpha 3^{*}$ chimeras. Data are presented as percent of ouabain-sensitive $\mathrm{Na}^{+}$-ATPase activity measured in absence of $\mathrm{KCl}$. Values, obtained from at least three different clones, are means \pm SE. At least three different membrane preparations were isolated for each clone and $\mathrm{Na}^{+}$-ATPase activity measurements were done in triplicate for each $\mathrm{K}^{+}$concentration.

changes were confirmed by examining the sensitivity of the reaction to $\mathrm{Li}^{+}$, which exhibits a faster relative rate of deocclusion than $\mathrm{K}^{+}$, thus emphasizing any differences. Exposure to $\mathrm{Li}^{+}$produced a frank stimulation of the ouabainsensitive $\mathrm{Na}^{+}$-ATPase activity (Figure 5) as described earlier by Daly et al. (15). Replacement of the $\alpha 1$ ISR by the H,Kor $m y c$ sequences induced subtle changes in $\mathrm{Li}^{+}$sensitivity at submillimolar concentrations, the major differences being found in the range of $1-5 \mathrm{mM}$ (Figure 5A). Chimeras derived from the $\alpha 3^{*}$ isoform displayed a dramatic sensitivity to $\mathrm{Li}^{+}$(Figure 5B). The $\mathrm{Li}^{+}$activation profiles of the constructed $\alpha 3$ chimeras were greatly enhanced as compared to the $\alpha 3 *$ isoform, the $\alpha 3 * \mathrm{HK} \alpha 3 *$ being the most sensitive to $\mathrm{Li}^{+}$. To summarize, data obtained from either $\mathrm{K}^{+}$or $\mathrm{Li}^{+}$ sensitivity experiments show that both $\alpha 1$ and $\alpha 3$ ISRs seem to influence enzyme kinetics.

The $\alpha 1$ ISR Is Implicated in PKC-Stimulated $\mathrm{Na}, \mathrm{K}$ ATPase-Mediated Transport. Earlier work by our laboratory using ISR exchanges among the isoforms suggests that this region contributes to the response of $\alpha 1$ to PKC-mediated phosphorylation (2). To evaluate further this contribution, we examined the effects of PKC stimulation on $\mathrm{Na}, \mathrm{K}$ ATPase-mediated transport in OK cells transfected with $\mathrm{H}, \mathrm{K}-$ 

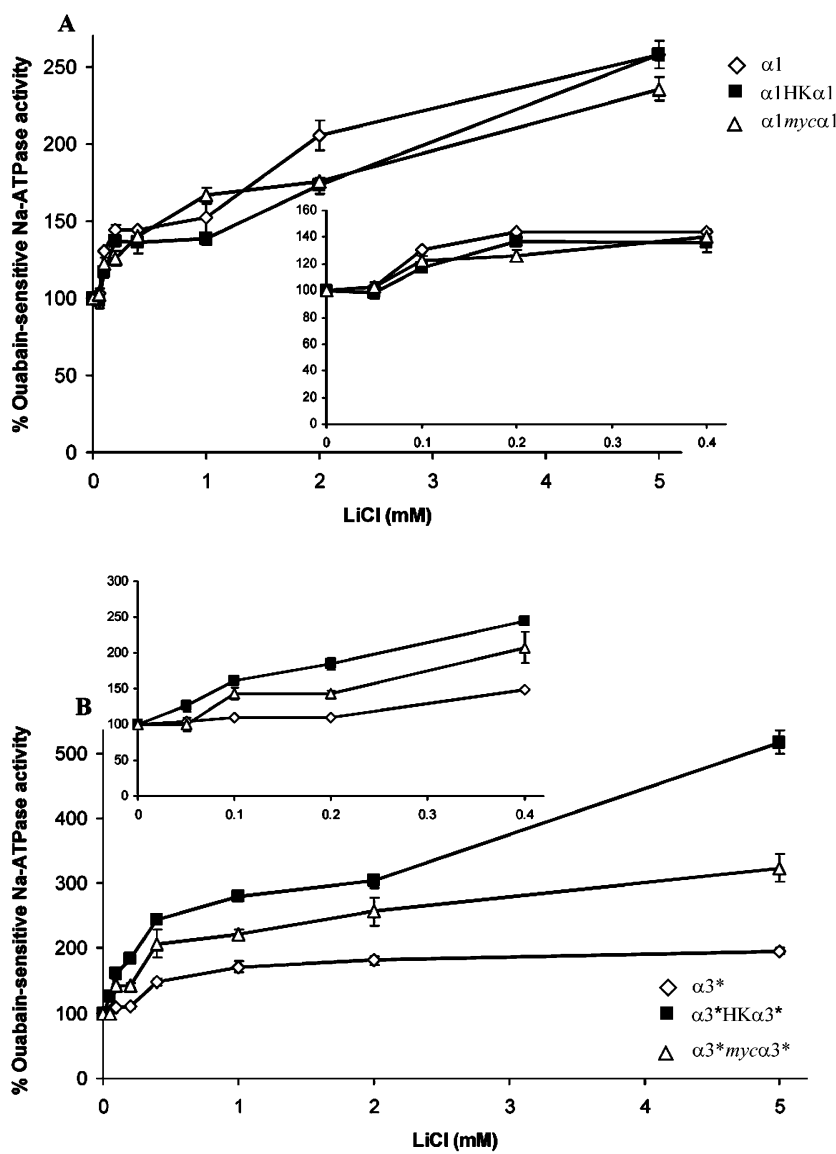

FIGURE 5: Relative $\mathrm{Li}^{+}$sensitivity of $\mathrm{Na}^{+}$-ATPase in membranes from transfected cells. Hydrolysis of $\left[\gamma-{ }^{32} \mathrm{P}\right] \mathrm{ATP}$ was measured after $30 \mathrm{~min}$ in the presence of $1 \mu \mathrm{M} \mathrm{ATP}, 20 \mathrm{mM} \mathrm{NaCl}$, and various concentrations of $\mathrm{LiCl}$. Results are presented relative to ouabainsensitive $\mathrm{Na}^{+}$-ATPase activity. To inhibit endogenous $\mathrm{Na}, \mathrm{K}$-ATPase $3 \mu \mathrm{M}$ ouabain was present in all reactions. (A) Ouabain-sensitive $\mathrm{Na}^{+}$-ATPase activity of $\alpha 1$ chimeras. (B) Ouabain-sensitive $\mathrm{Na}^{+}$ATPase activity of $\alpha 3^{*}$ chimeras. Data are presented as percent of ouabain-sensitive $\mathrm{Na}^{+}$-ATPase activity measured in absence of $\mathrm{LiCl}$. Values, obtained from at least three different clones, are means \pm SE. At least three different membrane preparations were isolated for each clone and $\mathrm{Na}^{+}$-ATPase activity measurements were done in triplicate for each $\mathrm{Li}^{+}$concentration. Inset: Shape of the various curves between 0 and $0.4 \mathrm{mM} \mathrm{Li}^{+}$shown in expanded scale.

ATPase- and $m y c$-substituted chimeras. Under basal conditions, ouabain-sensitive $\mathrm{Rb}^{+}$uptakes of transfected cells were similar to nontransfected OK cells $(8.6 \pm 0.5 \mathrm{nmol} \mathrm{K}+\mathrm{min} /$ $\mathrm{mg}$ proteins). Exposure to the PKC agonist PMA in the wildtype $\alpha 1$ transfected cells induced an increase in ouabainsensitive $\mathrm{Rb}^{+}$uptake of $15 \%$ (Figure 6A), as demonstrated previously $(2,16)$. Replacement of the $\alpha 1$ ISR by the rat gastric H,K-ATPase insert abolished the PMA-induced increase in ouabain-sensitive uptake. However, the PMA response was retained in the $\alpha 1$ myc $\alpha 1$-transfected cells, despite the presence of the unrelated $m y c$ sequence. Similar experiments with the $\alpha 3^{*}$ mutant revealed no evidence of PKC sensitivity (Figure 6B). To further investigate a potential role for the $\alpha 3$ ISR, experiments were conducted with three other $\alpha 3^{*}$ constructs. The $\alpha 3^{*} \alpha 1$ mutant, where the first 25 amino acids (including the serines phosphorylated by PKC) belonging to the $\mathrm{Na}, \mathrm{K}$-ATPase $\alpha 1$ isoform have been replaced by the $\alpha 3$ sequence, the $\alpha 3^{*} \alpha 1 \alpha 3^{*}$ and $\alpha 3^{*} \alpha 2 \alpha 3^{*}$ chimeras, where the $\alpha 3$ ISR has been exchanged by the rat
$\mathbf{A}$
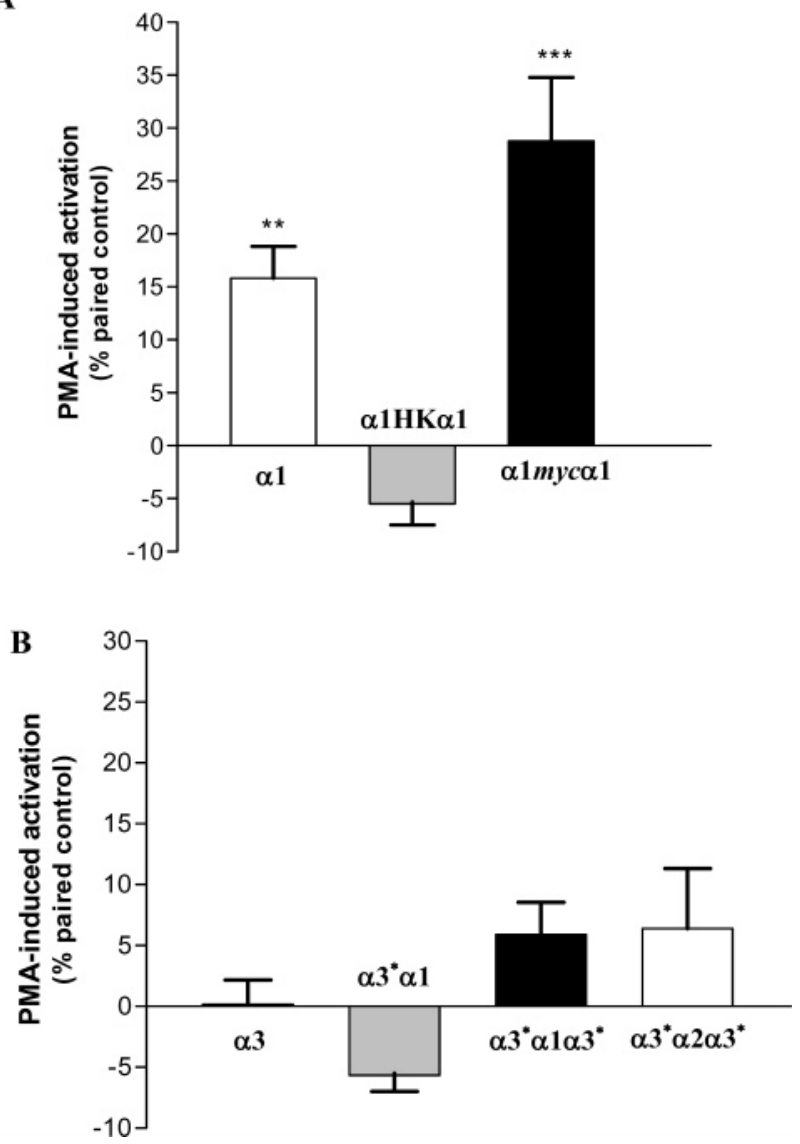

FIGURE 6: PMA-induced activation of Na,K-ATPase-mediated transport. $\mathrm{Na}, \mathrm{K}$-ATPase-mediated $\mathrm{Rb}^{+}$-transport was assayed by measuring the ouabain-sensitive uptake of the $\mathrm{K}^{+}$congener ${ }^{86} \mathrm{Rb}^{+}$ in attached cells exposed to $3 \mu \mathrm{M}$ or $1 \mathrm{mM}$ ouabain. PKC activation was induced by a $5 \mathrm{~min}$ exposure to $10 \mu \mathrm{M}$ PMA prior to the addition of $\mathrm{Rb}^{+}$. Values are means $\pm \mathrm{SE}(n=5$ in at least three different clones) and are expressed as the percentage of their paired controls, which represent the same cells exposed to the vehicle DMSO. Ouabain-sensitive $\mathrm{Rb}^{+}$uptakes of transfected cells were similar to nontransfected OK cells $(8.6 \pm 0.5 \mathrm{nmol} \mathrm{K}+\mathrm{min} / \mathrm{mg}$ proteins). (A) Transport of $\alpha 1$ chimeras. (B) Transport of $\alpha 3^{*}$ chimeras. The $\alpha 3^{*} \alpha 1$ mutant, where only the first 25 amino acids belong to the $\mathrm{Na}, \mathrm{K}$-ATPase $\alpha 3^{*}$ isoform, the $\alpha 3^{*} \alpha 1 \alpha 3^{*}$ and $\alpha 3^{*} \alpha 2 \alpha 3^{*}$ chimeras, where the ISR has been exchanged by the $\alpha 1$ and $\alpha 2$ ISRs, respectively, were constructed and transfected in OK cells. DMSO- and PMA-treated values from each transfection were compared using a two-tailed paired $t$-test. $* * p<0.01, * * * p$ $<0.001$ vs. paired controls.

Na,K-ATPase $\alpha 1$ and $\alpha 2$ ISRs, respectively, were constructed, sequenced, and transfected in OK cells as described previously. Na,K-ATPase-mediated $\mathrm{Rb}^{+}$-transport was then assayed by measuring the ouabain-sensitive uptake of ${ }^{86} \mathrm{Rb}^{+}$. Again, results did not reveal any changes in Na,K-ATPase transport after PKC stimulation by the phorbol ester PMA (Figure 6B). Similar results were obtained for the $\alpha 3^{*} \mathrm{HK} \alpha 3^{*}$ and $\alpha 3^{*} m y c \alpha 3 *$ chimeras (data not shown).

Taken together, the data from our earlier and present studies clearly support for an essential role of the $\alpha 1$ ISR in response to PKC phosphorylation. A similar role for the $\alpha 3$ ISR seems very unlikely.

Immunoblotting. To assess the expression of the Na,KATPase isoforms, our laboratory has designed specific antibodies against the rat $\alpha 1$ (named NASE) and, $\alpha 3$ (named TED) ISRs (17). Because these regions were altered in the chimeras, the isoform-specific antibodies were of little utility 
A

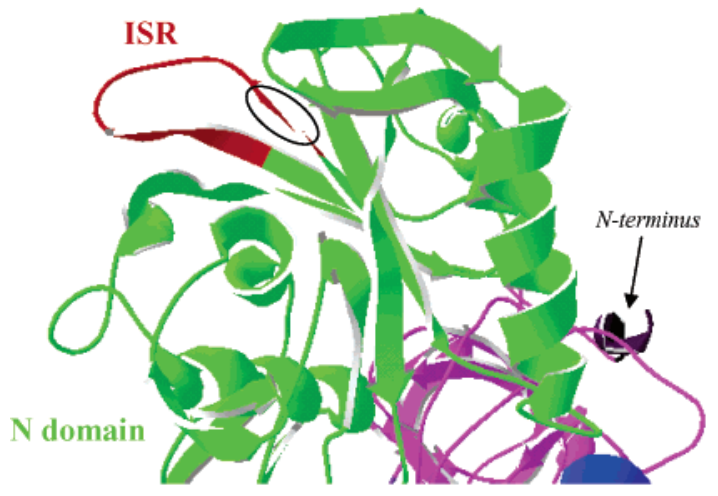

C

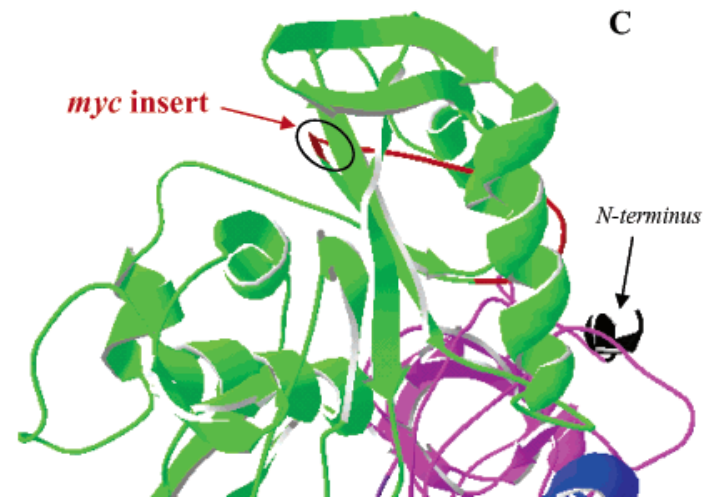

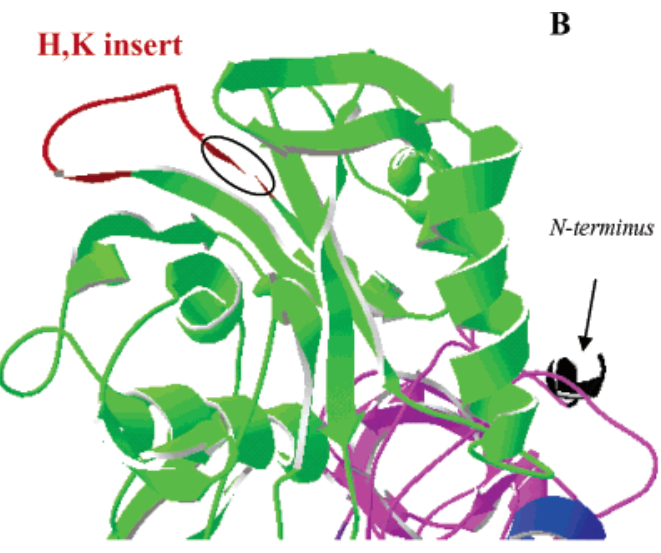

Analogous ISR

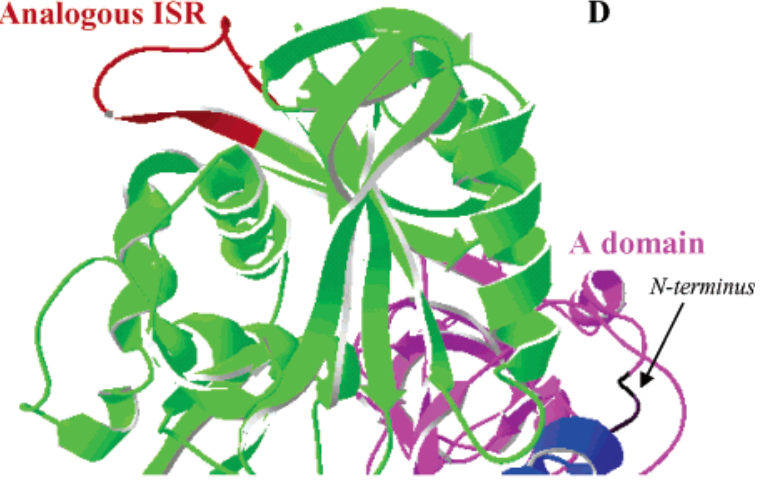

FIGURE 7: Comparisons of the 3-D structural model of the Na,K-ATPase catalytic $\alpha 1$ isoform with its corresponding chimeras. (A) Rat $\mathrm{Na}, \mathrm{K}-\mathrm{ATPase} \alpha 1$ isoform. (B) $\alpha 1 \mathrm{HK} \alpha 1$ chimera. (C) $\alpha 1$ myc $\alpha 1$ chimera. (D) Rabbit sarcoplasmic reticulum $\mathrm{Ca}^{2+}$-ATPase. Portions of the three cytoplasmic domains are represented: the actuator domain (A domain; residues 1-42 and 125-233) is in pink, the nucleotide domain ( $\mathrm{N}$ domain, residues 359-602) is in green and the phosphorylation domain (P domain, residues 330-357 and 605-740) is in blue. Two regions of the molecules are highlighted: the N-terminus is shown in black and the ISR or inserts are in red. Black circles indicate the location of the dileucine motifs. The models, based on the known 3-D structure of the sarcoplasmic reticulum Ca ${ }^{2+}$-ATPase isoform 1 (9, 10), were generated by the Swiss MODEL server and visualized using Deep View software (see Experimental Procedures for details).

when confirming the structures of the expressed mutant subunits. For the detection of the myc chimeras, we used the mouse monoclonal antibody 9E10 (Covance Research Products, Denver, PA) directed against the myc epitope. The antibody failed to detect a band in the transfected cells although it clearly detected appropriate controls (data not shown), suggesting that the myc epitope may not be accessible for antibody binding in the constructed myc chimeras. To evaluate the putative structural changes induced by the exchange of the ISR with the myc insert, structure modeling of the catalytic subunit of the Na,K-ATPase was performed.

Exchange of the ISR by Unrelated Sequences Leads to Structural Changes. A 3-D structural model of the rat Na,KATPase $\alpha 1$ isoform and its corresponding chimeras (Figure 7) based on the known structure of the sarcoplasmic reticulum $\mathrm{Ca}^{2+}$-ATPase $(9,10)$ was generated. The overall sequence identity between the sarcoplasmic reticulum $\mathrm{Ca}^{2+}$ ATPase and the sodium pump is around $30 \%$, and the sequence similarity between the two pumps is about $40 \%$. By existing criteria, this degree of identity and similarity is high enough to justify presuming that these proteins exhibit the same general protein folding patterns. This view is supported by data from Rice and co-workers (18), which show good agreement between the electron density maps of the $\mathrm{Na}, \mathrm{K}-\mathrm{ATPase}$ and the sarcoplasmic reticulum $\mathrm{Ca}^{2+}$ ATPase. Therefore, our model probably represents the actual $\mathrm{Na}, \mathrm{K}-\mathrm{ATPase}$ structure to a reasonably good approximation. Also, estimates from the 3DCrunch Project (see http://
www.expasy.ch/swissmod/SWISS-MODEL.html) indicate that $66 \%$ of models for which the target shares 30-39\% sequence identity with the template are correct with a rootmean-square difference value lower than $4 \AA$. Moreover, the crystal structure of the rat Na,K-ATPase $\alpha 1 \mathrm{~N}$-domain (19; PDB ID code: 1MO7) has been recently described. After superimposition of the $\mathrm{N}$-domain portion of our model with this new structure, we could observe that our model fits quite well with the new N-domain structure (data not shown) with a root-mean-squared deviation of $1.5 \AA$, which makes our model acceptable.

Such an analysis of the three-dimensional structure of the $\mathrm{Na}, \mathrm{K}-\mathrm{ATP}$ ase (Figure 7) reveals that the $\alpha 1$ ISR, located in the $\mathrm{N}$ domain of the Na,K-ATPase, is facing the cytoplasm and therefore is easily accessible for interaction with proteins. Introduction of the H,K-ATPase insert induced slight changes in the structure, while insertion of the myc epitope completely disrupted the likely structure of the region, which now faces the core of the protein and may therefore not be accessible for protein interaction (Figure 7). If this inaccessibility is retained after SDS-PAGE, this may explain why the myc antibody failed to detect the epitope of the constructed myc chimeras.

\section{DISCUSSION}

Several findings in the present study support an important role of the Na,K-ATPase $\alpha$ ISR in both enzyme kinetics and regulation of the pump by PKC. 
Indeed, after structural confirmation of the introduced rat isoforms and their correspondent chimeras using real-time PCR (Figures 2 and 3), we measured the ouabain sensitive $\mathrm{Na}^{+}$-ATPase activity at different $\mathrm{K}^{+}$or $\mathrm{Li}^{+}$concentrations to evaluate the impact of the $\alpha 1$ and $\alpha 3$ ISR exchanges. Similar to the results of Daly et al. (15) and Pierre et al. (2), we found that varying concentrations of $\mathrm{K}^{+}$, ranging from 0 to $5 \mathrm{mM}$, inhibited ouabain-sensitive $\mathrm{Na}^{+}$-ATPase activity in membranes from wild-type rat $\alpha 1$ - and $\alpha 3 *$-transfected OK cells (Figure 4), while similar concentrations of $\mathrm{Li}^{+}$lead to an activation profile (Figure 5) as described by Daly et al. (15). Although in our previous study (2), swapping of the $\alpha 1$ ISR with the $\alpha 2$ sequence did not induce any changes in $\mathrm{K}^{+}$sensitivity of the $\mathrm{Na}^{+}$-ATPase activity, replacement of the $\alpha 1$ and $\alpha 3$ ISRs with unrelated sequences in this study modified the $\mathrm{K}^{+}$inhibition as well as the $\mathrm{Li}^{+}$activation profiles to a notable extent (Figures 4 and 5). Indeed, changes of the $\alpha 1$ ISR by the HK and myc sequences both increased the $\mathrm{K}^{+}$-induced inhibition with the highest inhibition logically observed for the most dissimilar sequence, the c-myc epitope. Similar patterns for the $\mathrm{Li}^{+}$-induced activation were found for these chimeras at high $\mathrm{Li}^{+}$concentrations (Figure 5A). The results obtained for the $\alpha 3 *$ chimeras are more difficult to link in terms of homology of the inserted sequences to the original sequence. Indeed, although the c-myc sequence is the most dissimilar sequence, it behaves more like the wildtype $\alpha 3^{*}$ isoform than the $\alpha 3^{*} \mathrm{HK} \alpha 3^{*}$. Clearly, more work will be necessary to determine the specific structures within the $\alpha 3$ ISR that contribute to the rate of deocclusion. It seems likely, however, that the interactions in which the ISR participates may be more complicated than first imagined. Segall et al. (20) have suggested that three different domains in the $\alpha 1$ isoform, i.e., the amino terminus, the M2-M3 loop, and the M4-M5 catalytic loop (including the ISR), alter the transitions between the conformational states E1 and E2. It therefore may be that the ISR is involved in a complex threeway interaction.

In agreement with our previous study (2), this report confirms that the ISR is implicated in the response to second messengers. We have previously shown that phosphorylation of the $\alpha 1 \mathrm{~N}$-termini $\mathrm{Ser}^{11}$ and $\mathrm{Ser}^{18}$ by PKC increases $\mathrm{Na}, \mathrm{K}$ ATPase-mediated $\mathrm{Rb}^{+}$transport in cultured OK cells expressing the exogenous rat $\mathrm{Na}, \mathrm{K}-\mathrm{ATPase} \alpha 1$ isoform (21). This is the result of pump translocation from intracellular pools via clathrin-coated vesicles, leading to increased pump abundance in the plasma membrane. This process requires the phosphorylation of both $\operatorname{Ser}^{11}$ and $\operatorname{Ser}^{18}$ of the $\alpha 1$ isoform by the PMA-inducible PKC- $\beta$ isoform (21) and seems to involve a dileucine motif present in the $\alpha 1$ ISR, which would act as a dynamic retention signal favoring $\alpha 1$ internalization (2). Thus, the increase in $\alpha 1$ abundance after PMA treatment in OK cells seems to reflect a balance between translocation of intracellular pools of pumps to the plasma membrane and endocytosis of these same pumps, with an overall increase in $\mathrm{Na}, \mathrm{K}-\mathrm{ATPase}$ cell surface expression.

The dileucine motifs are characterized by a consensus sequence: (-)xxxLL, where $\mathrm{x}$ represents a polar residue and $(-)$ is an acidic residue, aspartic or glutamic acid (for review, see ref 22). The spacing between the acidic residue and the first leucine is crucial (23), whereas the requirement for the second leucine is more relaxed, as shown recently for the $\mathrm{Na}, \mathrm{K}-\mathrm{ATPase}$ by Doné et al. (24). The rat $\alpha 1$ isoform, used for the present study, displays a dileucine motif, ExxxLL, within the ISR. The analysis of the three-dimensional structure of the $\mathrm{Na}, \mathrm{K}$-ATPase revealed that this region is facing the cytoplasm, suggesting that the motif is easily accessible to interaction with clathrin, thereby promoting endocytosis of the pump. Although the protein expression of the $\alpha 1$ chimeras could not be evaluated in this study, we used the data obtained from the structure modeling to draw some hypotheses that might explain the changes in the PMA response observed for the $\alpha 1 \mathrm{HK} \alpha 1$ as well as for the $\alpha 1$ myc $\alpha 1$ chimeras. Substitution of the $\alpha 1$ ISR with the H,KATPase sequence, which like the $\alpha 1$ ISR contains a dileucine motif (DxxxLL), seemed to completely counteract the translocation of the Na,K-ATPase from intracellular pools to the plasma membrane, suggesting that this sequence is a better retention signal than the $\alpha 1$ ISR. As observed with the structural studies, introduction of the H,K-ATPase insert slightly changed the position of the dileucine motif, exposing it more to the surface of the protein where it may interact more efficiently with the proteins of the cellular endocytic machinery, as compared to the $\mathrm{Na}, \mathrm{K}$-ATPase $\alpha 1$ dileucine doublet, thereby promoting an increased endocytosis of the pump. Like the Na,K-ATPase, the gastric H,K-ATPase can be internalized by endocytosis, although it is thought to employ a tyrosine-based motif that resides in the cytoplasmic tail of the $\beta$-subunit (25). So far, no sequences in the catalytic subunit of the H,K-ATPase that could contribute to this process have been identified. The $\alpha 1$ myc $\alpha 1$ chimera also contains a dileucine doublet which is apparently inactive likely because of the conformational changes introduced by the myc insert. Indeed, as seen in Figure 7, insertion of the myc insert completely disrupted the likely structure of the region with the dileucine motif, which now faces the core of the protein and may therefore not be accessible to interaction with proteins. As a result, internalization of the chimeric polypeptide might be abolished, leading to an increase in pump abundance in the plasma membrane and in Na,K-ATPase-mediated transport after PMA treatment, as observed in this study. To confirm these hypotheses, future studies will include quantification of protein expression in different cell fractions (plasma membrane, early/late endosomes, and clathrin-coated vesicles) in the absence and presence of the phorbol ester.

Although it is well-known that PKC-mediated phosphorylation of the $\alpha 1$ isoform occurs at Ser-11 and 18, it still remains unclear which residues are phosphorylated in the $\alpha 2$ and $\alpha 3$ isoforms. Even though these two serines are absent in the $\alpha 2$ isoform, Pierre et al. (2) documented that exposure of $\alpha 2 *$-transfected cells to phorbol esters produces an increase in pump-mediated transport similar to the one observed for $\alpha 1$. In view of these results and because of the presence of a dileucine motif in the $\alpha 3$ ISR, we investigated whether phorbol esters could also modify the Na,K-ATPasemediated transport of the $\alpha 3$ isoform. Our results show that activation of PKC- $\beta$ by PMA in OK cells transfected with the $\alpha 3^{*}$ mutant failed to change basal Na,K-ATPasemediated transport. Although the $\alpha 3$ isoform is a poor substrate for PKC, phosphorylation of this isoform by PMA occurs, but only at $\mathrm{Ser}^{14}$ in Xenopus oocytes (26) corresponding to $\operatorname{Ser}^{18}$ in the rat $\alpha 1$ isoform. As PMA-induced $\mathrm{Na}, \mathrm{K}-\mathrm{ATPase}$ transport requires the phosphorylation of both $\mathrm{Ser}^{11}$ and $\mathrm{Ser}^{18}$ in the $\alpha 1$ isoform, we can speculate that, as 
with the $\alpha 1$ isoform (21), phosphorylation of only one serine residue in the $\alpha 3$ isoform may be not sufficient to induce the cellular response to PMA. Also, exchange of the $\alpha 3$ ISR with the analogous region of $\alpha 1$ or $\alpha 2$ did not modify the pump-mediated transport in response to PMA (Figure 6B), suggesting that the ISR does not represent the main component involved in the regulation of the pump by protein kinase $\mathrm{C}$.

The results of the present study clearly demonstrate that, the ISR, located in the $\mathrm{N}$ domain, seems to play an important role in both enzyme kinetics and $\mathrm{PKC}$ regulation of the pump in OK cells. This region may interact with the phosphorylated serines $\left(\operatorname{Ser}^{11}\right.$ and $\operatorname{Ser}^{18}$ ) located in the amino terminus (domain $\mathrm{A}$ ) of the $\mathrm{Na}, \mathrm{K}-\mathrm{ATPase} \alpha 1 \mathrm{E}_{2}(2 \mathrm{~K})$ form as described by Jorgensen et al. (27). Future experiments will determine the importance of the dileucine motif in PKC regulation.

\section{ACKNOWLEDGMENT}

We would like to thank Dr. Juan Codina for his critical review and comments.

\section{REFERENCES}

1. Blanco, G., and Mercer, R. W. (1998) Isozymes of the Na-KATPase: heterogeneity in structure, diversity in function, Am. J. Physiol. 275, F633-F650.

2. Pierre, S. V., Duran, M.-J., Carr, D. L., and Pressley, T. A. (2002) Structure/function analysis of $\mathrm{Na}^{+}-\mathrm{K}^{+}$-ATPase central isoformspecific region: Involvement in $\mathrm{PKC}$ regulation, Am. J. Physiol. 283, F1066-F1074.

3. Shull, G. E., Greeb, J., and Lingrel, J. B. (1986) Molecular cloning of three distinct forms of the $\mathrm{Na}^{+}, \mathrm{K}^{+}$-ATPase alpha-subunit from rat brain, Biochemistry 25, 8125-8132.

4. Shanbaky, N. M., and Pressley, T. A. (1994) Mammalian $\alpha 1$ subunit of $\mathrm{Na}^{+}-\mathrm{K}^{+}$-ATPase does not need its amino terminus to maintain cell viability, Am. J. Physiol. 267, C590-C597.

5. Jewell, E. A., and Lingrel, J. B. (1991) Comparison of the substrate dependence properties of the rat $\mathrm{Na}, \mathrm{K}$-ATPase $\alpha 1, \alpha 2, \alpha 3$ isoforms expressed in HeLa cells, J. Biol. Chem. 266, 1692516930 .

6. Lane, L. K., Copenhaver, J. H., Lindenmayer, G. E., and Schwartz, A. (1973) Purification and characterization of and $\left[{ }^{3} \mathrm{H}\right]$ ouabain binding to the transport adenosine triphosphatase from outer medulla of canine kidney, J. Biol. Chem. 248, 7197-7200.

7. Lowry, O. H., Rosebrough, N. J., Farr, A. L., and Randall, R. J. (1951) Protein measurement with the Folin phenol reagent, J. Biol. Chem. 193, 265-275.

8. Petrosian, S. A., Carr, D. L, Guerrero, G., and Pressley, T. A. (1998) Mutagenesis disrupts posttranslational processing of the Na, K-ATPase catalytic subunit, Arch. Biochem. Biophys. 357, 249-258.

9. Toyoshima, C., and Nomura, H. (2002) Structural changes in the calcium pump accompanying the dissociation of calcium, Nature 418, 605-611.

10. Toyoshima, C., Nakasako, M., Nomura, H., and Ogawa, H. (2000) Crystal structure of the calcium pump of sarcoplasmic reticulum at $2.6 \AA$ resolution, Nature $405,647-655$.
11. Guex, N., and Peitsch, M. C. (1997) SWISS-MODEL and the Swiss-PdbViewer: an environment for comparative protein modeling, Electrophoresis 18, 2714-2723.

12. Peitsch, M. C. (1996) ProMod and Swiss-Model: Internet-based tools for automated comparative protein modeling, Biochem. Soc Trans. 24, 274-279.

13. Vilsen, B. (1993) Glutamate 329 located in the fourth transmembrane segment of the alpha-subunit of the rat kidney $\mathrm{Na}^{+}, \mathrm{K}^{+}$ ATPase is not an essential residue for active transport of sodium and potassium ions, Biochemistry 32, 13340-13349.

14. Daly, S. E., Lane, L. K., and Blostein, R. (1996) Structure/function analysis of the amino-terminal region of the $\alpha 1$ and $\alpha 2$ subunits of Na, K-ATPase, J. Biol. Chem. 271, 23683-23689.

15. Daly, S. E., Lane, L. K., and Blostein, R. (1994) Functional consequences of amino-terminal diversity of the catalytic subunit of the Na, K-ATPase, J. Biol. Chem. 269, 23944-2394.

16. Pedemonte, C. H., Pressley, T. A., Lokhandwala, M. F., and Cinelli, A. R. (1997) Regulation of Na, K-ATPase transport activity by protein kinase C, J. Membr. Biol. 155, 219-227.

17. Pressley, T. A. (1992) Phylogenetic conservation of isoformspecific regions within $\alpha$-subunit of $\mathrm{Na}^{+}-\mathrm{K}^{+}$-ATPase, Am. J. Physiol. 262, C743-C751.

18. Rice, W. J., Young, H. S., Martin, D. W., Sachs, J. R., and Stokes, D. L. (2001) Structure of $\mathrm{Na}^{+}, \mathrm{K}^{+}$-ATPase at 11- $\mathrm{\AA}$ resolution: comparison with $\mathrm{Ca}^{2+}$-ATPase in E1 and E2 states, Biophys. J. 80, 2187-2197.

19. Hilge M., Siegal G., Viuster G. W., Guntert P., Gloor S. M., Abrahams J. P. (2003) ATP-induced conformational changes of the nucleotide-binding domain of Na, K.-ATPase, Nat. Struct. Biol. $10,468-474$.

20. Segall, L., Lane, L. K., and Blostein, R. (2002) New insights into the role of the $\mathrm{N}$ terminus in conformational transitions of the Na, K-ATPase, J. Biol. Chem. 277, 35202-35209.

21. Efendiev, R., Bertorello, A. M., Pressley, T. A., Rousselot, M. Feraille, E., and Pedemonte, C. H. (2000) Simultaneous phosphorylation of Ser11 and Ser18 in the $\alpha$-subunit promotes the recruitment of $\mathrm{Na}^{+}, \mathrm{K}^{+}$-ATPase molecules to the plasma membrane, Biochemistry 39, 9884-9892.

22. Kirchhausen, T. (1999) Adaptors for clathrin-mediated traffic, Annu. Rev. Cell. Dev. Biol. 15, 705-732.

23. Dietrich, J., Kastrup, J., Nielsen, B. L., Ødum, N., and Geisler, C. (1997) Regulation and function of the CD3 $\gamma$ DxxxLL motif: A binding site for adaptor protein-1 and adaptor protein-2 in vitro, J. Cell. Biol. 138, 271-281.

24. Cotta Done, S., Leibiger, I. B., Efendiev, R., Katz, A. I., Leibiger, B., Berggren, P.-O., Pedemonte, C. H., and Bertorello, A. M. (2002) Tyrosine 537 within the $\mathrm{Na}^{+}, \mathrm{K}^{+}$-ATPase $\alpha$-subunit is essential for AP-2 binding and clathrin-dependent endocytosis, J. Biol. Chem. 277, 17108-17111.

25. Courtois-Coutry, N., Roush, D., Rajendran, V., McCarthy, J. B., Geibel, J., Kashgarian, M., and Caplan, M. J. (1997) A tyrosinebased signal targets $\mathrm{H} / \mathrm{K}$-ATPase to a regulated compartment and is required for the cessation of gastric secretion, Cell 90, 501510 .

26. Beguin, P., Peitsch, M. C., and Geering, K. (1996) $\alpha 1$ but not $\alpha 2$ or $\alpha 3$ isoforms of $\mathrm{Na}, \mathrm{K}$-ATPase are efficiently phosphorylated in a novel protein kinase C motif, Biochemistry 35, 14098-14108.

27. Jorgensen, P. L., Hakansson, K. O., and Karlish, S. J. D. (2003) Structure and mechanism of Na, K -ATPase: Functional sites and their interactions, Annu. Rev. Physiol. 65, 817-849.

BI0490183 